\title{
Neonatal Pulmonary Hemorrhage, AE
}

National Cancer Institute

\section{Source}

National Cancer Institute. Neonatal Pulmonary Hemorrhage, AE. NCI Thesaurus. Code C154936.

An adverse event in a newborn characterized by bleeding in the respiratory tract of a neonate. 